\title{
0 dispositivo de enunciação da primeira universidade com sistema de cotas do Nordeste ${ }^{1}$
}

\author{
The mechanism of enunciation of the first university to adopt \\ the system of quotas in the Northeast of Brazil
}

El dispositivo de enunciación de la primera universidad que contó con el sistema de cuotas en el Nordeste de Brasil

\section{Lidiane Santos de Lima Pinheiro}

- Doutora em Comunicação e Cultura Contemporâneas pela Universidade Federal da Bahia (UFBA), com estágio doutoral na Université Paris X (Nanterre)

- Mestre em Literatura e Diversidade Cultural pela Universidade Estadual de Feira de Santana (UEFS) - Bahia

- Professora adjunta do Curso de Relações Públicas da Universidade do Estado da Bahia (Uneb)

- Membro dos grupos de pesquisa de Análise do Discurso Mediático (Cepad) e de Análise de Marca (Logos), da UFBA

- E-mail: Lidicom@yahoo.com

1 Trabalho originalmente intitulado "O dispositivo de enunciação da primeira universidade com sistema de cotas do Nordeste: análise semiodiscursiva da comunicação organizacional da Uneb", apresentado no GP de Semiótica da Comunicação do XVI Encontro dos Grupos de Pesquisa em Comunicação, evento componente do XXXIX Congresso Brasileiro de Ciências da Comunicação (Intercom 2016). 


\section{Resumo}

0 artigo analisa o discurso da primeira universidade com sistema de cotas do Nordeste, a Universidade do Estado da Bahia (Uneb), observando a construção de seu ethos, seu contrato de comunicação e sua posição de enunciação em campanhas de vestibular, e o compara com o discurso de outra instituição de ensino superior, a Unijorge. Verifica-se que a Uneb, com uma posição pedagógica, mas cúmplice, constrói a imagem de instituição inclusiva e afrodescendente, diferentemente da Unijorge, cujo discurso hedonista revela o lugar de fala do jovem branco de classe média.

\section{PALAVRAS CHAVE: ANÁLISE DO DISCURSO • COMUNICAÇÃO ORGANIZACIONAL・DISPOSITIVO DE ENUNCIAÇÃO}

\section{Abstract}

The article analyzes the speech of the first university to adopt the system of quotas in the Northeast of Brazil, Universidade do Estado da Bahia (Uneb), observing the construction of its ethos, its communication contract and its position of enunciation in entrance examination campaigns, and compares it with the speech of another college education institution, Unijorge. By the work developed, it can be seen that Uneb, with a pedagogical but complicit position, constructs the image of an inclusive and Afro-origin institution, unlike Unijorge, which hedonistic speech reveals the place of voicing of the middle-class white youth.

\section{KEYWORDS: SPEECH ANALYSIS•ORGANIZATIONAL COMMUNICATION・MECHANISM OF ENUNCIATION.}

\section{Resumen}

Este trabajo investiga el discurso de la primera universidad que contó con el sistema de cuotas en la región nordeste de Brasil, la Universidad del Estado de Bahía (Uneb), observando la construcción de su imagen y su posicionamiento frente a los públicos. Para eso, el artículo trabaja con los conceptos de contrato de comunicación, ethos y posición de enunciación, a partir de los cuales se analizan las piezas publicitarias del examen de ingreso de la Uneb, y se las compara con campañas publicitarias de otra institución de educación superior de Salvador, la Unijorge. Se observa que la Uneb, con una posición pedagógica, pero cómplice, construye la imagen de institución inclusiva y afrodescendiente, a diferencia de la Unijorge, cuyo discurso hedonista revela el lugar de habla del joven blanco de clase media. 
presente artigo resulta de uma pesquisa intitulada "Análise do discurso da comunicação organizacional"2, que trabalha com a organizacional pelo viés dos estudos do discurso, buscando contribuir com tal interface, ao direcionar um novo olhar para as práticas na área, antes lida como um percurso linear de informações transmitidas da organização ao público-alvo.

Entende-se a comunicação organizacional como a confluência de atividades comunicacionais - comunicação administrativa, institucional, mercadológica e interna (Kunsch, 2003) - que visam melhorar as relações entre a organização e os públicos. Para isso, são criadas, articuladas e comunicadas filosofia, visão e missão da organização; são sedimentadas a identidade e a imagem institucional; e são produzidas estratégias de comunicação que visam promover a organização, mas também compatibilizar seus interesses com os dos diversos públicos.

Para além desta definição, comunicação organizacional, conforme explicada por Rudimar Baldissera (2008, apud Baldissera; Stocker, 2015, p. 146), é um "processo de construção e disputa de sentidos no âmbito das relações organizacionais", pois nelas os sentidos são constantemente construídos, desconstruídos e reconstruídos. A comunicação organizacional é, portanto, um processo circular e interacional que possibilita a assimilação, a rejeição ou a modificação dos sentidos inicialmente propostos. Sob tal perspectiva, visamos entender mais sobre o porquê de determinadas escolhas enunciativas e como são construídas as estratégias discursivas nesse campo. Para tanto, partimos do princípio de que pode ser designado como discurso "qualquer conjunto significante considerado como tal (isto é, considerado como lugar de investimento de sentido), quaisquer que sejam as matérias significantes em questão (a linguagem propriamente dita, o corpo, a imagem etc.)" (Verón, 2004, p. 61).

Propomos estudar o discurso da comunicação organizacional da Universidade do Estado da Bahia (Uneb), por ser a primeira universidade a adotar o sistema de cotas raciais do Nordeste e a maior instituição pública de ensino superior da Bahia (em tamanho e capilaridade), estando distribuída em vinte e quatro campi, além dos outros municípios nos quais se faz presente por ações extensionistas. Visamos analisar a construção do seu dispositivo de enunciação, observando como o enunciador constrói uma imagem de si e se posiciona frente a seus públicos.

A importância de compreendermos como se constrói o dispositivo de enunciação justifica-se pelo fato de ele comportar: a imagem de quem fala (enunciador), a imagem daquele a quem o discurso é endereçado (destinatário ou coenunciador) e a relação entre estes dois sujeitos - ou estas duas "entidades discursivas", logo, não empíricas -, "que é proposta no e pelo discurso" (Verón, 2004, p. 218, grifo do autor). Logo, tal conceito é importante para estudarmos o funcionamento social dos enunciados em comunicação organizacional. Ainda de acordo com Eliseo Verón, "todo suporte de imprensa contém seu dispositivo de enunciação", que, neste caso, ele chama também de "contrato de leitura". E quanto à comunicação organizacional, como isso se dá? Qual seria o dispositivo de enunciação ou o contrato de leitura/de comunicação, particularmente, na relação da Uneb com seus públicos?

Para entendermos como se estrutura o dispositivo de enunciação da Uneb, analisando a imagem que esse enunciador constrói de si, do seu destinatário e da relação entre os dois, operacionalizaremos os conceitos de contrato de leitura/ comunicação, ethos e posição de enunciação; e selecionaremos, para a análise, peças de divulgação dos vestibulares 2014 , 2015 e, sobretudo, 2016. Buscando conclusões mais firmes sobre o dispositivo de enunciação investigado, traçaremos uma breve comparação dele com o contrato de leitura/comunicação firmado por outra instituição de ensino superior da Bahia junto a seus públicos, a Unijorge, diferenciando-o ou aproximando-o da forma como a Uneb constrói o seu contrato. Para isso, também analisaremos suas campanhas publicitárias de vestibular de 2014 a 2016.

2 Pesquisa desenvolvida com a colaboração dos bolsistas de iniciação científica da Fundação de Amparo à Pesquisa do Estado da Bahia (Fapesb) Emanuelle Pereira, Lucas de Sant'Anna Lucas e João Paulo Brito Alves (Uneb). 


\section{REFERENCIAL TEÓRICO E OPERADORES DE ANÁLISE}

Toda comunicação humana tem por base um princípio de cooperação, segundo o qual os interlocutores conhecerão e respeitarão certas regras. É esse acordo tácito, socialmente compartilhado, que possibilita a construção e a circulação de qualquer discurso. A suposição de que o outro possui as competências enciclopédicas e linguageiras para a compreensão do dito pelo locutor compõe uma espécie de contrato implícito de comunicação entre as duas partes (Charaudeau, 2008).

0 contrato de comunicação, então, seria um conjunto de representações idealizadas sobre o outro/interlocutor, sobre 0 enunciado e sobre a própria relação comunicacional, que a legitima e dá pistas de sua condução. Em sequência à definição de contrato, Charaudeau (2008, p. 56) explica a noção de estratégia discursiva, que

repousa na hipótese de que o sujeito comunicante (EUc) concebe, organiza e encena suas intenções de forma a produzir determinados efeitos - de persuasão ou de sedução - sobre o sujeito interpretante (TUi), para levá-lo a se identificar - de modo consciente ou não - com o sujeito destinatário ideal (TUd) construído por EUc.

Vale lembrar que, como Verón (2004), Charaudeau (2008) diferencia o emissor empírico (externo ao discurso), que ele chama de sujeito comunicante, do enunciador (interno ao discurso); e, da mesma forma, o sujeito interpretante, que seria o indivíduo 'de carne e osso' que recebe a comunicação, do destinatário ideal, que seria o leitor/público "modelo", detectável pela análise do discurso.

Reflitamos agora sobre um caso em particular. Como pensar as estratégias discursivas e os contratos de comunicação na arena enunciativa das publicidades de vestibular? São inúmeros jovens concluindo o ensino médio, ávidos pela entrada no nível superior, e umas tantas universidades e faculdades tentando chamar a sua atenção. Para além das promessas comuns que tais instituições buscam firmar em seus contratos de comunicação (como a qualidade de ensino), as estratégias discursivas mudam, a partir da identidade e dos valores que cada marca representa, bem como dos supostos saberes e expectativas específicas do seu público. Por isso, concordamos com Verón: mais do que o que o enunciado diz, importa 0 como diz, ou seja, as modalidades do dizer, pois são estas que dão forma ao dispositivo de enunciação.

Partimos, então, da hipótese de que o discurso publicitário das instituições de ensino superior de um mesmo estado, que possuem, portanto, semelhanças em seus contratos de comunicação, revelam-se diferentes, não necessariamente no plano do conteúdo, mas, sim, no das estratégias discursivas e, logo, nos dispositivos de enunciação, construtores de um vínculo particular com seus públicos. Para avaliar tal hipótese, o primeiro aspecto a investigar, no que concerne ao dispositivo de enunciação na comunicação organizacional, é a posição de enunciação:

A posição de enunciação pedagógica define o enunciador e o destinatário como desiguais: o primeiro mostra, explica, aconselha; o segundo olha, compreende, tira proveito. A posição de enunciação 'distanciada' e não-pedagógica induz uma certa simetria entre 0 enunciador e o destinatário: o primeiro, mostrando uma maneira de ver as coisas (...), convida o destinatário a adotar o mesmo ponto de vista ou, pelo menos, a apreciar a maneira de mostrar tanto quanto o que é mostrado. É a razão pela qual essa enunciação 'distanciada' volta a propor ao destinatário um jogo em que o enunciador e o destinatário se rencontram na cumplicidade criada pela partilha de certos valores culturais (Verón, 2004, p. 230-1, grifos do autor).

Os discursos de comunicação organizacional podem revelar: uma posição de enunciação pedagógica/didática, quando classificam, hierarquizam, quantificam e deixam clara a diferença entre o saber do coenunciador e o do enunciador (a universidade, no caso); uma posição distanciada, objetiva e impessoal; ou de cumplicidade e diálogo, que interpela e mobiliza valores culturais reconhecíveis pelos públicos. 
Posição didática ou não, transparência ou opacidade, distância ou diálogo, objetividade ou cumplicidade, partilha de valores no nível do dito ou no plano das modalidades do dizer (...), grau e tipo de saber atribuídos ao leitor: por meio das escolhas efetuadas em relação a essas dimensões (que, é claro, admitem graus) e a muitas outras, constrói-se o contrato de leitura: apresenta-se um enunciador que propõe um lugar a um destinatário (Verón, 2004, p. 233).

É isso que buscaremos fazer aqui: escavar os enunciados, destacando as pistas que denunciam a posição do enunciador, principalmente, mas também a do destinatário ideal e, com isso, resgatar o contrato que a Uneb constrói com seu principal público externo (jovem do ensino médio e outros possíveis candidatos ao vestibular) por meio da sua comunicação organizacional..

A posição de enunciação revela traços de quem é o coenunciador idealizado pelo enunciador, mas também da imagem que ele tenta construir de si. 0 ethos discursivo ${ }^{3}$ é isso: a personalidade do locutor revelada nas marcas do enunciado. Não necessariamente representará seus reais atributos nem será dito na enunciação. "Sua eficácia decorre do fato de que envolve de alguma forma a enunciação sem ser explicitado no enunciado" (Maingueneau, 2006, p. 69).

Todo discurso possui, segundo Maingueneau (2008, p. 72), um ethos, ou seja, uma "vocalidade específica, que permite relacioná-lo a uma fonte enunciativa, por meio de um tom que indica quem o disse". É como se o enunciador - a própria instituição, no caso da Uneb - tivesse um tom de voz reconhecível em todas as suas falas. Sempre que tal marca se manifesta, seu enunciado tem (ou espera-se que tenha) a mesma vocalidade, o mesmo tom que o identifica. Tal vocalidade corporifica a instância do enunciador, atribuindo-lhe determinações e um caráter mais ou menos preciso - com base em um arsenal de estereótipos ou representações coletivas ancoradas em uma cultura. "Assim a leitura faz emergir uma origem enunciativa, uma instância subjetiva encarnada que exerce o papel de fiador" (Maingueneau, 2008, p. 72). Logo, o ethos, além de atribuir ao enunciador um tom de voz (que seria algo como um estilo pessoal, um mesmo modo de enunciar), dá-lhe corpo (sugestões de características físicas) e personalidade ("feixe de traços psicológicos"). A fim de analisar o ethos da Uneb, buscaremos responder a questões como: é uma instituição jovem? Masculina? Branca? Conservadora? Essa construção é feita pelo público com base em indícios de diversas ordens: gênero do discurso, uso de primeira ou segunda pessoa no texto, presença ou ausência de gírias, características físicas dos modelos nas imagens etc.

A partir dos conceitos explicados, a seguir realizaremos a análise discursiva das peças de comunicação organizacional selecionadas, mas, antes, faremos uma breve apresentação da Assessoria de Comunicação (Ascom), setor responsável por toda a comunicação oficial da Uneb.

\section{A COMUNICAÇÃO ORGANIZACIONAL DA UNEB}

A assessoria de comunicação da Uneb está sediada no Campus 1, em Salvador. Ela tem por função produzir e gerenciar toda a comunicação oficial dos vinte e quatro campi da universidade espalhados pelo Estado da Bahia. Todo o material produzido pela Ascom é resultado de um planejamento anual, do qual participam os quatro setores da assessoria: 0 Núcleo de Jornalismo (NuJor), o de Relações Públicas (NuRP), o de Design (NucDesign) e o de Áudio Visual (Navi).

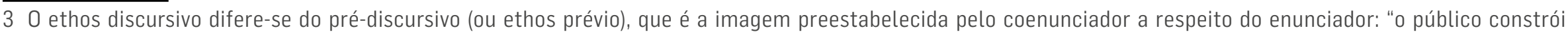
representações do ethos do enunciador antes mesmo que ele fale" (Maingueneau, 2008, p. 71). 
Para o público interno ${ }^{4}$, a Ascom elabora campanhas esporádicas (como a de avaliação institucional), além dos informes do site, das redes sociais e do e-mail; mas a comunicação mais regular que encontramos, particularmente direcionada aos funcionários, são os cartões comemorativos ${ }^{5}$ enviados pelo e-mail institucional e publicados nas redes sociais. Para o público externo, a maior, mais regular e, logo, principal ação de comunicação ${ }^{6}$ são as campanhas de vestibular, compostas por cartazes, outdoors, frontlights, peças para o site institucional e as redes sociais etc. A justificativa da importância desta ação, que extrapola a simples divulgação do processo seletivo, pode ser lida no plano da campanha de divulgação do vestibular 2016 (Ascom-Uneb, 2015, p. 3):

É preciso compreender o momento de divulgação do vestibular não somente para capturar inscrições, mas motivar a adesão de estudantes a real identidade institucional e também por entender que pensar uma campanha de divulgação é uma tarefa com consequências que ultrapassam um período específico - de inscrições - e, indo além desse período, reverbera na imagem institucional. A constituição e o fortalecimento da imagem institucional é um processo constante. No caso da Uneb, o vestibular é o momento em que a organização fica em evidência. Assim, a escolha do tema e da forma como a campanha de divulgação será conduzida torna-se fundamental para o sucesso da empreitada e, também, para a imagem da universidade.

Entendemos que uma das principais funções do anúncio publicitário, veículo central de uma campanha de divulgação como a do vestibular, é atualizar oficialmente o discurso da instituição frente aos seus públicos, incluindo o público interno, que reforçará (ou rejeitará) a imagem da marca ali manifesta. Daí a relação da publicidade com a comunicação organizacional:

A publicidade constitui-se em importante e fundamental processo dinamizador do discurso organizacional na medida em que potencializa sua visibilidade e abrangência (...). Por meio da publicidade, as organizações selecionam aspectos de suas identidades para colocar em circulação e propor sentidos aos seus públicos, sendo essa fala oficial, legítima e autorizada (Baldissera; Stocker, 2015, p. 147).

Além de anunciar produtos ou serviços e dar visibilidade a determinada organização/marca, a publicidade naturaliza modos de ser e estar no mundo, ao propor valores que, sendo aceitos pelo público, são capazes de sugerir horizontes de sentido que o ajudarão a interpretar a sua própria experiência cotidiana, tornando-se parte de seu projeto de vida (SEMPRINI, 2010). Vejamos como a Uneb faz isso em suas campanhas para o vestibular.

Figura 1: Vestibular 2014 e 2015.

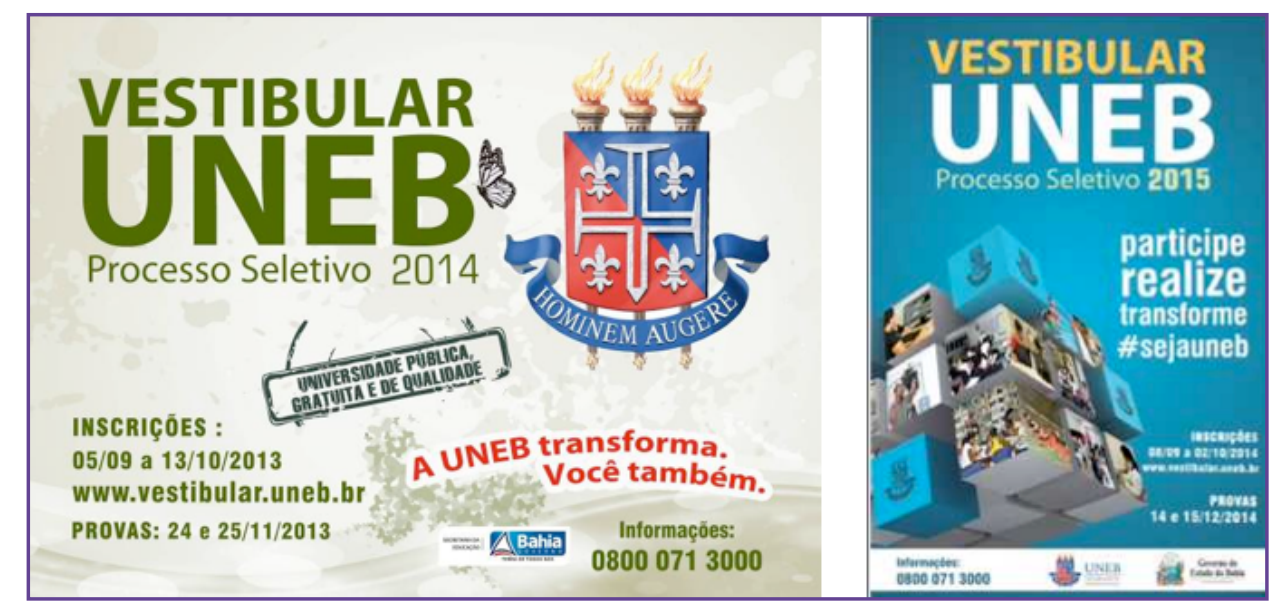

Fonte: Ascom-Uneb.

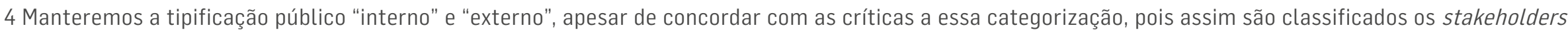
pela Ascom-Uneb.

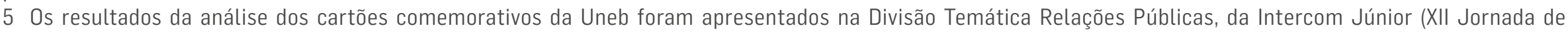

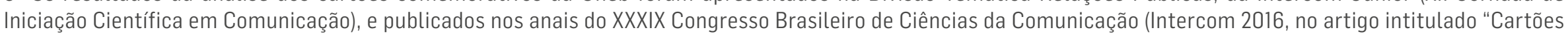

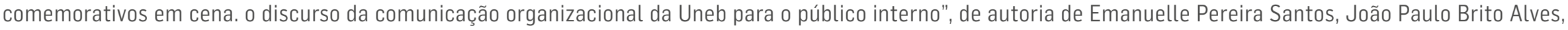
Lucas de Sant'Anna Fernandes Lucas e Lidiane Santos de Lima Pinheiro. Disponível em: <http://portalintercom.org.br/ anais/nacional2016/index.htm>.

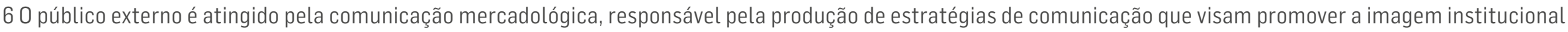
ou a venda de serviço/produto.
} 
Nos anos 2014 e 2015, o discurso das campanhas vestibulares da Uneb (Figura 1) pode ser resumido no verbo "transformar". Ele aparece no sintagma "A Uneb transforma. Você também" (2014), sugerindo a transformação do mundo e do candidato - futuro universitário - pela instituição de ensino; e também no ícone da borboleta que, por seu conhecido processo de metamorfose, é símbolo de transformação - saber enciclopédico que se espera do destinatário. No ano seguinte (2015), o enunciador o interpela pelo uso do imperativo: "participe, realize, transforme, \#sejauneb", mantendo o discurso de transformação associado à universidade e ao vestibulando, que, uma vez aprovado e inserido neste universo, deve ser ativo e reproduzir seu orgulho de "ser Uneb" nas redes sociais.

Outros elementos que se destacam em ambas as peças são os signos da relação metonímica de uma unidade (ou do todo - a universidade) constituída por partes dela representativas: em 2014, o grande ícone da borboleta é formado por borboletas menores; em 2015, o cubo mágico é formado por pequenos cubos (compostos pela logomarca e por índices fotográficos que remetem à Uneb), também congruentes, com lados, arestas e ângulos independentes, mas cuja movimentação de uma das peças implica a movimentação das demais. A Uneb, com isso, põe em relevo o seu caráter multicampi como diferencial em relação às outras instituições de ensino superior da Bahia e, em paralelo, valoriza a participação do alunado, que transformaria e formaria a universidade.

O ethos que aí se constrói, portanto, é o de um mestre que acredita na capacidade do discente de entender sua mensagem - por possuir os saberes requisitados - e de ser partícipe na transformação proposta. Para isso, ele se posiciona pedagogicamente, no momento em que apresenta e hierarquiza as informações sobre o vestibular (respondendo à expectativa do público de saber quando acontecerá e como obter mais informações), mas diminui o efeito de distanciamento entre quem, a princípio, possui o saber e aquele que ainda não o obteve, ao dialogar diretamente com o destinatário, interpelando-o pelo uso do "você", na primeira peça, e pelo imperativo, na segunda, que não deixa dúvidas de que o sujeito comunicante busca uma relação mais próxima com o sujeito interpretante, fazendo-o se identificar com o destinatário ideal. Esse efeito de sentido de cumplicidade é reforçado pelo uso da hashtag \#sejauneb, uma vez que tal signo serve para marcar a existência da universidade no ciberespaço, comumente frequentado pelo jovem que prestará vestibular.

Figura 2: Cartaz do Vestibular Uneb 2016

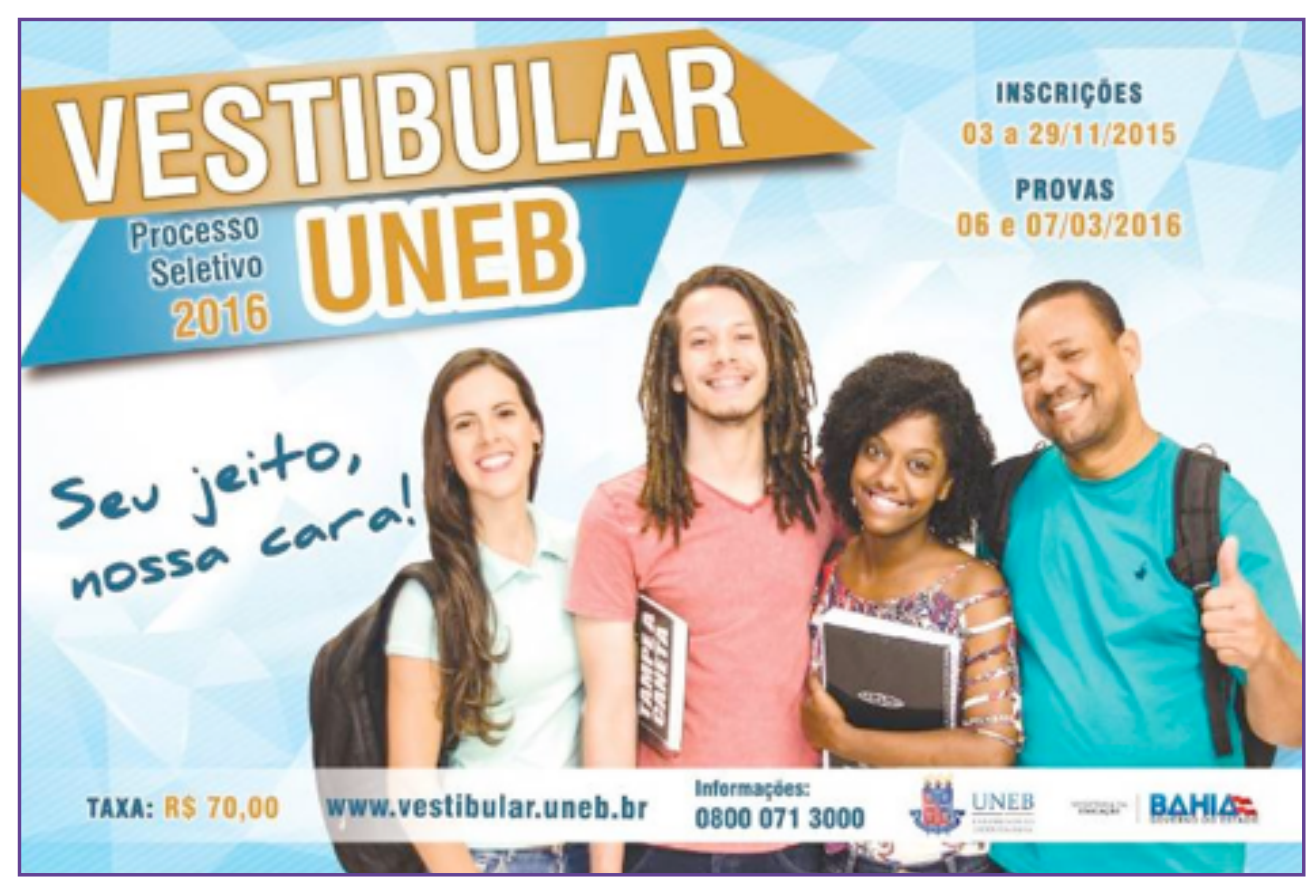

A campanha para o vestibular 2016 envereda por outras estratégias discursivas, apesar do objetivo comum de "incentivar a adesão dos estudantes de ensino médio à Uneb, fortalecendo sua imagem institucional no estado" (Ascom-Uneb, 2015, 
p. 5). Usando modelos humanos, personagens reais da própria instituição (alunos da Uneb e não modelos pagos ${ }^{7}$ ), as peças são mais simples e lembram a campanha de 2012 (Figura 3). Sem signos que remetam ao caráter multicampi da universidade nem que falem diretamente em transformação, o único efeito de sentido que se mantém claramente, em relação às peças de 2014 e 2015, é o de diálogo do enunciador com o jovem aspirante a uma vaga na universidade. Mais uma vez interpelando-o, pelo olhar dos personagens da foto e, na frase, pelo uso da segunda pessoa do singular, na campanha de 2012, o enunciador declara: "Um mundo possível começa com você" - o que, indiretamente, toca na questão da transformação do mundo pela participação/intervenção do destinatário.

Figura 3: Frontlight do Vestibular Uneb 2012.

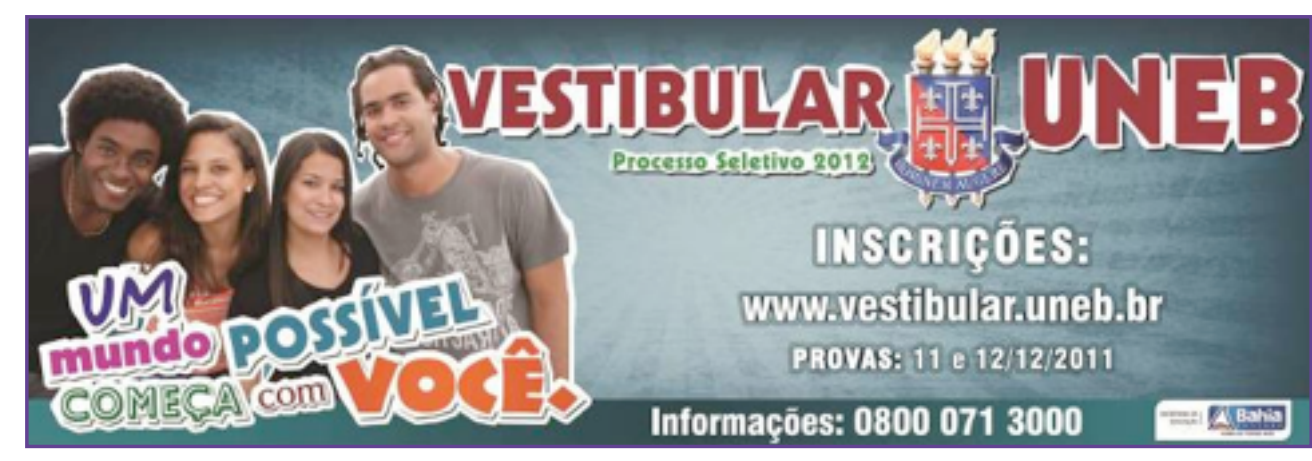

Em 2016, o slogan da campanha, "Seu jeito, nossa cara" (Figura 2), atualiza o efeito de sentido de conversação entre os interlocutores, pelo uso de um substantivo informal e típico do diálogo entre jovens ("cara"), antecedido pelo pronome "nossa", que indica a assunção de quem fala: uma primeira pessoa pluralizada pelo fato de o enunciador ser um grupo/uma organização. Quem fala é um "nós" composto por quem se identifica com a universidade e se sente parte dela. Mas o que é mesmo a "nossa cara"? Ou seja, o que identifica a face mais imediata da Uneb e a singulariza? "Seu jeito". 0 que diferenciaria a marca Uneb, portanto, segundo tal discurso, seriam as características do coenunciador (destinatário idealizado na enunciação): vestibulando, particularmente aquele que será aprovado e de quem podemos traçar um perfil, pelo passado de entradas na universidade. Quem é ele? Quem é o estudante da Uneb, que foi candidato nos vestibulares anteriores e cujo jeito é a cara da instituição? A resposta está na representação escolhida para figurar as duas campanhas publicitárias. Quatro jovens, dois de cada gênero, segurando, na peça do ano de 2016 (Figura 2), objetos indiciais de estudo (mochilas e cadernos), usando vestimentas despojadas e sem nenhum sinal de ascensão social/riqueza material: dois pardos, dois negro(a)s e nenhum branco/loiro. Difícil definir a etnia pela cor da pele dos personagens, mas o cabelo pode ser lido como um signo da assunção de uma identidade: em 2012, dois lisos (alisados?), um crespo e um rasta; em 2016, um liso, um rasta e dois crespos.

A Universidade do Estado da Bahia implantou seu sistema de cotas raciais (que reserva $40 \%$ das vagas para afrodescendentes que cursaram o ensino médio em escola pública e $5 \%$ para indígenas) em 2002, criando um modelo que passou a ser seguido por outras instituições de ensino superior. Mesclando critérios sociais e raciais no processo seletivo de seu vestibular, a Uneb foi a primeira universidade do Nordeste e a segunda do Brasil a implantar tal modelo de ações afirmativas, atrás apenas da Universidade do Estado do Rio de Janeiro (Uerj), e foi referência para as leis de cotas sancionadas pela presidente Dilma Rousseff dez anos depois ${ }^{9}$. Além disso, a atual gestão ampliou as políticas de inclusão, com a criação da Pró-Reitoria de Ações Afirmativas (Proaf), a fim de dar condições de permanência dos seus estudantes ingressos por cotas nos seus cursos.

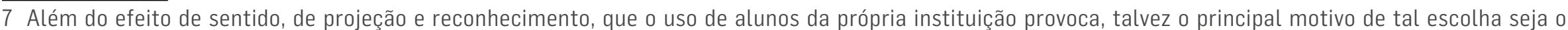

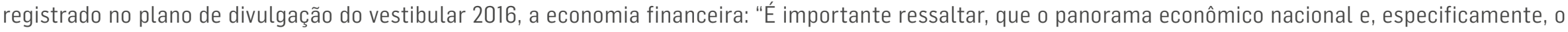

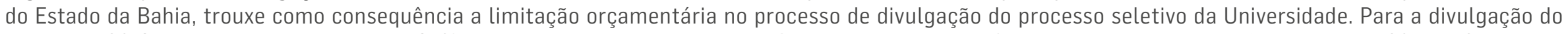
vestibular 2016, temos a redução de quase 65\% do valor destinado ao Plano de Mídia executado pela Agência Tempo Propaganda" (Ascom-Uneb, 2015, p. 3).

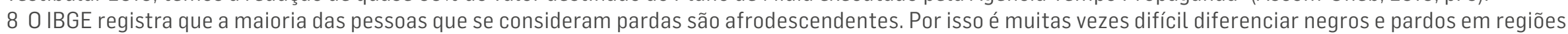
com muita miscigenação, como na Bahia.

9 Disponível em: <http://www.uneb.br/2012/09/11/uneb-foi-referencia-na-lei-de-cotas-aprovada-pela-presidenta-dilma/>. Acesso em: 01 jul 2016.
} 
A inclusão é algo que diz respeito diretamente aos estudantes que desejam ingressar na universidade. Primeiramente, porque estes estudantes, muitas vezes desiludidos por acharem o ingresso em uma universidade pública um sonho muito distante, precisam saber que a Uneb tem procurado ampliar as oportunidades de acesso, tornando esse sonho cada vez mais realizável. Em segundo lugar, os estudantes precisam saber que, em nossa universidade, encontrarão um ambiente respeitoso e acolhedor, no qual poderão encontrar toda assistência necessária para proceder e concluir com seu curso de graduação (Ascom-Uneb, 2015, p. 10).

Todas as ações citadas e este fragmento do plano da campanha vestibular explicam o ethos da instituição como uma universidade inclusiva (na qual, além das ações afirmativas, o aluno não-cotista acolhe o cotista) e não-branca (ou formada por um público identificado como negro ou pardo), conforme vimos no discurso analisado.

Como garantir, contudo, que o dispositivo de enunciação da Uneb também não seja típico das demais instituições de ensino superior da Bahia, cuja população afrodescendente é uma das maiores do Brasil? Chegar a uma conclusão segura sobre tal questão demandaria um esforço de pesquisa muito maior do que o visado neste artigo, devido à quantidade de instituições de ensino superior do estado, mas nada nos impede de pincelarmos uma comparação para mantermos um parecer mais firme sobre como a Uneb busca se diferenciar e construir um contrato singular com seus públicos. Para isso, escolhemos um dos maiores centros universitários de Salvador, a Unijorge (antiga Faculdade Jorge Amado), pela grande visibilidade que ganhou sua campanha vestibular 2016 nos outdoors das principais regiões da cidade.

Figura 4: Peças publicitárias do Vestibular Unijorge 2016.

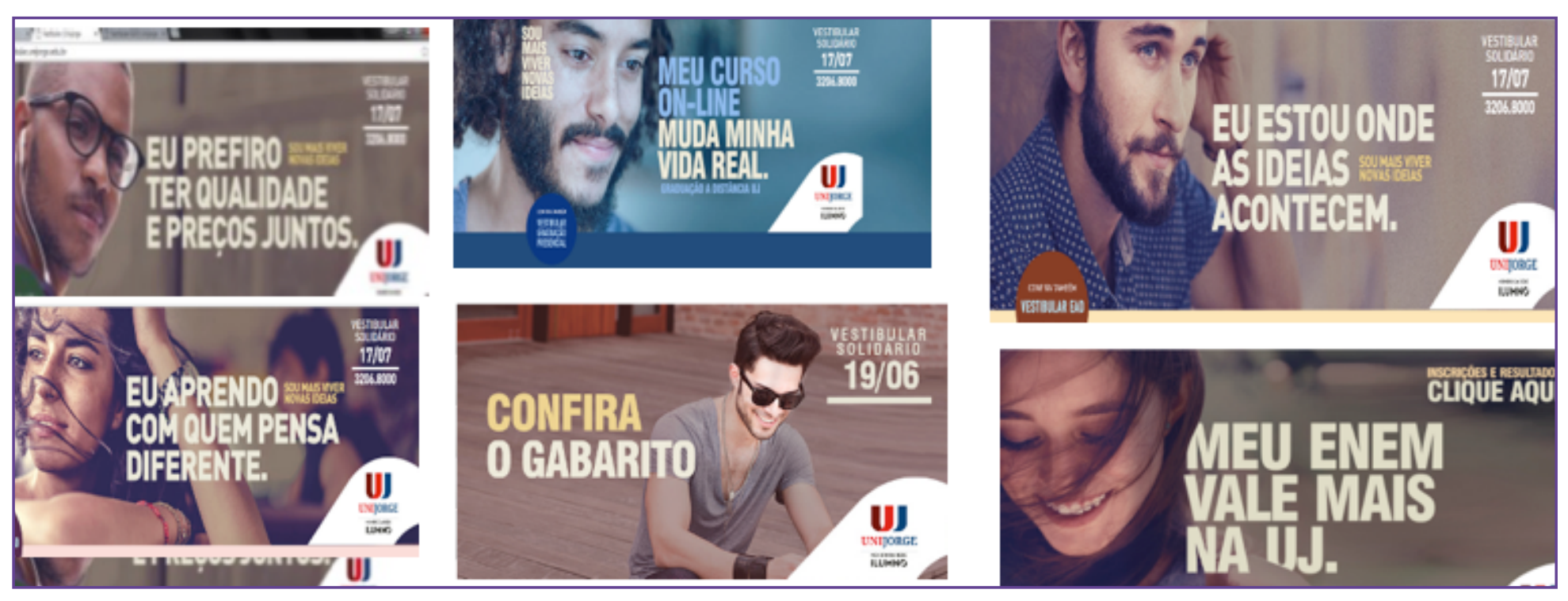

Fonte: < http://www.unijorge.edu.br/>. Acesso em: 05 jul. 2016.

Temos aqui (Figura 4) seis exemplares das peças da campanha do vestibular 2016 da Unijorge, que, além de figurar em cartazes, outbus e outdoors da cidade, podiam ser encontradas no site institucional, junto às informações sobre o processo seletivo para os cursos presenciais e de ensino a distância (EAD). 0 slogan da campanha, "Sou mais viver novas ideias", sinaliza o que nos parece a maior proposta do dispositivo de enunciação do centro universitário, no diálogo com seu público estudantil, e o grande valor vendido pela marca: a vivência de novas ideias e/ou experiências. No site institucional, confirmamos nossa hipótese:

Acreditamos fortemente que, além da excelência acadêmica e da qualidade de serviços, a formação profissional dos nossos alunos passa por uma vivência universitária singular e memorável. É isso que buscamos oferecer a toda comunidade Unijorge: experiências incríveis para ser feliz, para ser mais, para fazer a diferença ${ }^{10}$.

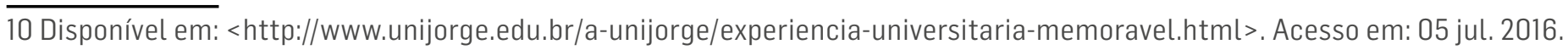


Vender uma abstração ligada ao valor juvenil de viver uma "experiência memorável" e "incrível" para "ser feliz" e "fazer a diferença" foi o mote de outras campanhas da Unijorge, como a intitulada "Eu vivo sonhos reais" (2014)" e a "Sou mais viver experiências" (2015)12. Os spots, assim como a campanha de 2016, usam a primeira pessoa do singular, representando a voz do próprio estudante, a quem o enunciador Unijorge dá voz, diferentemente da forma dialógica com que a Uneb estrutura seu enunciado. 0 sentido de subjetividade de tais campanhas está marcado pelo "eu" e por pronomes possessivos de primeira pessoa em frases como: "euvivo minhas escolhas, meus caminhos, minhas histórias, euvivo buscando e, com isso, aprendendo. Euvivo construindo o meu mundo. Não adianta esperar pelos outros, quando eu posso fazer a diferença"13. Tais sintagmas produzem o efeito de sentido de valorizar a independência nas escolhas que o jovem faz e, nesta fase da vida - de alguém da classe média ou média-alta, que compõe o público-alvo da instituição -, esse anseio caminha paralelo ao de uma carreira profissional. As imagens sugerem a individualidade na busca por novas experiências, pois nunca aparecem mais de duas pessoas agrupadas, do que concluímos que, enquanto a Uneb reforça uma identidade sempre ligada à comunidade (de estudantes ou dos vários campl), a Unijorge projeta sua marca pela valorização de um certo hedonismo.

Figura 5: Campanha do Vestibular Unijorge 2014 - \#Euvivosonhosreais.

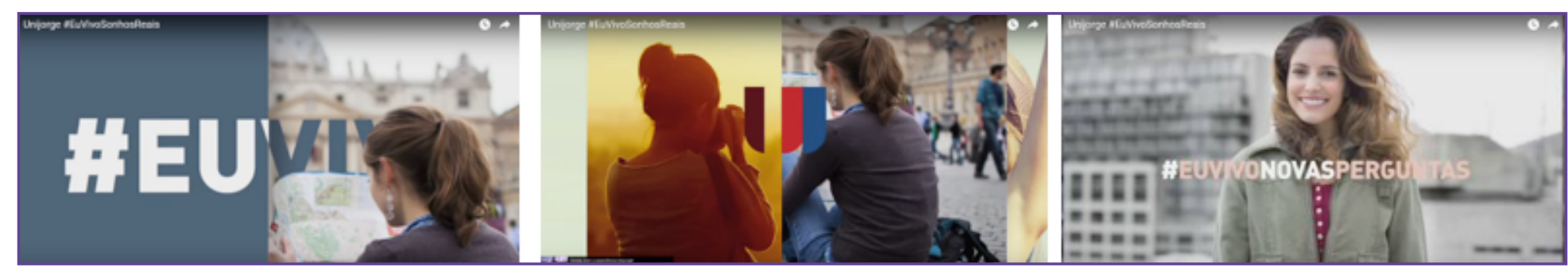

Fonte: <https://www.youtube.com/watch?v=quL272UJg4Q>. Acesso em: 05 jul. 2016

É notável também, na campanha de 2014 da Unijorge, que as imagens (Figura 5) não parecem ser da Bahia (o que é reforçado pelo uso de vestimentas de frio pela maioria dos modelos) e algumas sugerem viagem - nelas, os personagens estão com um mapa, uma grande máquina fotográfica etc. Isso é ratificado na campanha de 2015, quando os personagens vestibulandos falam dos seus planos: "quero passar um ano na Europa vendo o que é tendência por lá. (...) quero morar fora um tempo. (...) não vejo a hora de viajar de mochila nas costas" - como se a entrada na Unijorge possibilitasse a futura concretização desse sonho comum do jovem brasileiro de classe média. Por fim, é sintomático o fato de só aparecer, muito rapidamente, uma pessoa negra no primeiro spot e nenhuma no segundo. No de $2016^{14}$, porém, assim como nas peças de imagens paradas, a representação do negro se faz mais presente. Ainda assim, não deixa de ser minoria e grande parte dos outros personagens tem cabelos lisos e traços típicos do embranquecido padrão ocidental moderno de beleza. É significativo, nesse contexto, que a única frase ligada ao preço é a do negro, como se este se identificasse necessariamente com alguém de classe baixa, mas que teria também oportunidade de entrar no centro universitário. No mais, nenhum índice de baianidade, além da logomarca azul e vermelha (mesmas cores da logo da Uneb), cujo nome remete ao escritor Jorge Amado, pela experiência colateral que se espera do público.

\section{CONSIDERAÇÕES FINAIS}

Como explicam Baldissera e Stocker (2015), as organizações são sujeitos em interação, cuja comunicação é resultado de um processo circular de disputas de sentido. Quando enunciam, elas se posicionam e, assim, estabelecem com

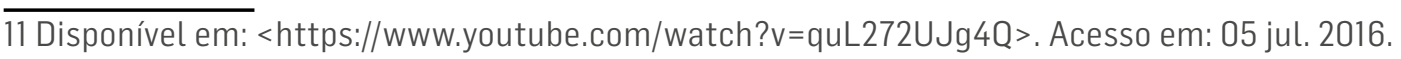

12 Disponível em: <https://www.youtube.com/watch?v=iWyXRL60qlE>. Acesso em: 05 jul. 2016.

13 Disponível em:< https://www.youtube.com/watch?v=quL272UJg4Q. Acesso em: 05 jul. 2016.

14 Disponível em: <https://www.youtube.com/watch?v=tFr49L7KPP8>. Acesso em: 05 jul 2016. 
seus interlocutores (públicos) um contrato de comunicação, a partir do qual legitimam seu discurso e se diferenciam dos concorrentes. Nesse percurso, as organizações acabam produzindo uma imagem de si (ethos), com vocalidade e personalidade encarnadas em uma corporalidade - num jogo de projeção realizado/atualizado pelo coenunciador. Diante desse processo completamente relacional, não há como continuar admitindo a comunicação organizacional como um simples e linear fluxo informativo vindo das organizações para os públicos. Se a Uneb e a Unijorge espelham nos seus ethos as expectativas e características identificadas nos seus públicos, é pela contínua necessidade de reorganizar sua enunciação em prol dos sentidos produzidos por estes.

Projetando o ethos de uma universidade que tem a cor da pele ou a etnia da maioria dos baianos, a Uneb constrói um discurso de inclusão e de valorização da identidade afrodescendente (independentemente de a cor ser negra ou parda), ao passo que instituições particulares de ensino superior da Bahia, a exemplo da Unijorge, pincelam a presença do negro em suas campanhas publicitárias, geralmente, representando aqueles que não têm a mesma condição financeira do seu público-alvo, mas que ainda assim poderiam ter chance de estudar no centro universitário.

Outra diferença que se faz marcante é a valorização do "eu" pela Unijorge, em um discurso verbal e visual bem comum entre as demais faculdades particulares da Bahia (no qual geralmente aparece apenas um indivíduo), ao passo que a Uneb sempre constrói seu discurso pelo uso da metonímia: o todo-universidade é construído pelas partes, que seriam os vários campi ou a participação do alunado.

Sem a mesma qualidade final das peças da Unijorge, a Uneb usa o recurso de que dispõe (estudantes da própria universidade) para atrair um público diverso para o vestibular, apesar de majoritariamente jovem e das classes B e $C$, e para reforçar sua imagem de instituição inclusiva. Quanto à posição de enunciação, é pedagógica, ao hierarquizar e explicitar com clareza as informações, ainda que o discurso construa um efeito de sentido de aproximação e diálogo com o jovem vestibulando; ao passo que a Unijorge tem uma posição de enunciação cúmplice, dando voz ao coenunciador, que fala em primeira pessoa. Por fim, ainda que as campanhas mudem o foco a cada ano, o dispositivo de enunciação da Uneb parece sempre pautar os mesmos valores: o compromisso com a comunidade, com a inclusão do afrodescendente e a comunicação com o jovem estudante, a quem propõe uma experiência de transformação ou diálogo.

Como toda análise de discurso, a realizada aqui não almejou dar a última palavra sobre o objeto pesquisado nem se exaurir. Partindo do princípio de que toda ação em comunicação organizacional resulta em uma construção discursiva, propomos entender os modos de enunciação nesse campo, que se dá por meio de estratégias discursivas para a promoção de efeitos de sentido positivos à organização, mas que nem sempre vão se efetivar na interpretação dos públicos - polo não investigado no presente estudo. Nesse sentido, no que concerne às pesquisas em comunicação organizacional, buscamos dar uma luz de como operacionalizar conceitos da análise do discurso e, sobretudo, contribuir com a desnaturalização dos fenômenos estudados.

\section{REFERÊNCIAS}

ASCOM-UNEB. Vestibular 2016: comunicação e divulgação. Salvador: Ascom-Uneb, 2015.

BALDISSERA, Rudimar; STOCKER, Pâmela. Comunicação organizacional e ethos discursivo: estratégias para falar de si nos anúncios dos bancos. IN: MARQUES, Ângela C. S.; OLIVEIRA, Ivone de L. (Orgs.). Comunicação organizacional: dimensões epistemológicas e discursivas. Belo Horizonte: UFMG, 2015. p. 146-162. 
CHARAUDEAU. Patrick. Linguagem e discurso. São Paulo: Contexto, 2008.

CHARAUDEAU, Patrick; MAINGUENEAU, Dominique. Dicionário de análise do discurso. São Paulo: Contexto, 2004.

KUNSCH, Margarida M. Krohling. Planejamento de relações públicas na comunicação integrada. 4. ed. - rev., atual. e ampl. São Paulo: Summus Editorial, 2003.

MAINGUENEAU, Dominique. Cenas da enunciação. Curitiba: Criar, 2006.

. Ethos, cenografia, incorporação. In: AMOSSY, Ruth (Org.). Imagens de si no discurso: a construção do ethos. São Paulo: Contexto, 2008. p. 69-92.

SEMPRINI, Andrea. A marca pós-moderna: poder e fragilidade da marca na sociedade contemporânea. São Paulo: Estação das Letras e Cores, 2010.

VERÓN, Eliseo. Fragmentos de um tecido. São Leopoldo, RS: Unisinos, 2004.

Texto recebido em 30.02.2017 e aprovado em 26.05.2017. 